\title{
SELLing ORgans ETHICALLY: DisENTANGLING EXPLOITATION ARGUMENTS
}

\author{
Hui Min Loh
}

\begin{abstract}
This essay explores the possibility of an ethical market for organs. To this end, I first analyse and evaluate the exploitation claims that have been raised in objection to a market for organs. This includes an examination of the characteristics of exploitation that distinguish it from other types of wrongs. Following that, the essay turns to the moral force of such exploitation arguments in relation to a market for organs. I suggest that such exploitation claims point to a regulated 'ethical' market as opposed to prohibition. I conclude by attempting to construct an ethical market that would best answer critics as well as protect the welfare of the individuals involved.
\end{abstract}

\section{A. SCOPE OF THE PAPER}

This paper will look at proposals for a market in organs for therapeutic purposes, the removal of which will not be fatal to the individual. Organs are defined in s. 7(2) of the Human Organs Transplant Act 1989, as 'a structured arrangement of tissues which, if wholly removed, cannot be replicated by the body.'

At the outset, I acknowledge, but do not seek to explore in great detail, proposed alternatives to a market system including incentives like donor medals of honour, ensuring access to organs for previous donors and tax breaks. ${ }^{1}$ I am also aware of proposals for a market in cadaveric organs, ${ }^{2}$ but will primarily focus on an organ market comprised of live vendors. This is because while the success rate of organ transplants from live persons far exceeds that of cadaveric organs, ${ }^{3}$ the rate of unrelated live donations is exceedingly low in this country ( 801 between 2009 and 2010). ${ }^{4}$ A market is thought to be the most effective way of increasing the supply of organs from live persons. Further, a market in cadaveric organs,

\footnotetext{
1 Andy H. Barnett and David L. Kaserman, 'The Shortage of Organs for Transplantation: Exploring the Alternatives' (1993) 9 Issues L. \&Med 117, 125.

2 ibid.

3 Michael Nicholson and J Andrew Bradley, 'Renal transplantation from living donors', (1999) 318 British Medical Journal 409-410.

${ }^{4}$ UK Transplant Transplant Activity Statistics, available from

<www.uktransplant.org.uk> accessed on 24 September 2012.
} 
though hardly less morally problematic, rarely raises the questions of exploitation that I am interested in.

Finally, I recognize the existence of a raging debate over property in body parts and whether they can be bought and sold. ${ }^{5}$ This paper will begin from the presumption that our body parts are alienable and can be bought and sold.

\section{B. Disentangling Exploitation Arguments}

The paid donor in a developing country is usually poor and ignorant concerning the whole process of organ donation and transplantation, and may be open to both coercion and exploitation and thus the loss of autonomy. The practice of the poor selling their organs to the rich tacitly endorses the inequality of society and represents the ultimate exploitation of the poor by the rich. $^{6}$

Why do we first need to disentangle the concept of exploitation? Whilst frequently invoked as an argument against organ markets, little thought has been given to it as a moral concept. As Wertheimer notes, the meaning and moral force of exploitation are not self evident. ${ }^{7}$ There can be no meaningful debate without first understanding what the various exploitation claims mean.

The term 'exploitation', broadly defined as 'using something for a purpose, ${ }^{8}$ has both moral and non-moral senses. When we say that we exploit a natural resource or talent, we use the term in a morally neutral manner. However, the term 'exploitation' may also be used normatively to express moral disapproval (as in the above quote). ${ }^{9}$ For clarity, I use 'exploitation' throughout this paper in the normative sense to mean wrongful exploitation or to suggest a presupposed account of wrongful exploitation.

\footnotetext{
${ }^{5}$ For example see Margaret Radin, 'Property and Personhood' (1982) 34 Stanford Law Review 957.

${ }^{6}$ J. Stewart Cameron and Raymond Hoffenberg, 'The ethics of organ transplantation reconsidered: paid organ donation and the use of executed prisoners as donors' (1999) 55 Kidney International 727.

${ }^{7}$ Alan Wertheimer, Exploitation (Princeton: Princeton University Press, 1996) 5.

8 Justin Schwartz, 'What's wrong with exploitation?' (1995) 29 Nous 176.

9 Onora O'Neill, 'Between Consenting Adults' (1985) 14 Philosophy and Public Affairs 252.
} 
As seen above, most exploitation arguments against an organ market have largely focussed on the possible exploitation of poor and desperate vendors. However, the converse could also be true. A patient looking to purchase an organ can be as, if not more, desperate and therefore vulnerable to exploitation. How this affects the case against a market for organs will be explored below. Finally, there are different views on what constitutes exploitation in organ sales. On one view, organ sales are exploitative because purchasers gain from the transaction while vendors are on balance harmed either in the non moral sense (harmful exploitation) or by being treated merely as a means as opposed to an end (wrongful use). On another, the vendor gains from the transaction but in a way that is unfair to him (mutually advantageous exploitation). Assuming that exploitation claims have a definable moral content and are not merely used to express moral repugnance, what makes a transaction wrongfully exploitative?

\section{Truth Conditions of an Exploitation Claim}

Exploitation of persons consists in wrongful behaviour but it would be untrue to state that any wrongful behaviour will warrant this description. It is wrong to murder, rape or steal from others but we do not apply to these wrongs the label 'exploitation'. Our task is to pick out the characteristics of exploitation that distinguish it from other types of wrong.

In my opinion, there are least two essential conditions of an exploitative transaction: it benefits the exploiter and is unfair to the exploited party. As a working definition, exploitation occurs when one party takes unfair advantage of another party ${ }^{10}$ by failing to benefit the disadvantaged party as fairness requires. ${ }^{11}$

\section{The Benefit Condition}

The benefit to the exploiter distinguishes exploitation from other wrongs such as discrimination or abuse. ${ }^{12}$ For instance, A might be behaving in a

\footnotetext{
${ }^{10}$ Wertheimer (n 7) 6.

11 Robert Mayer, 'What's Wrong with Exploitation' (2007) 24:2 Journal of Applied Philosophy 137, 138.

${ }^{12}$ Wertheimer (n7) 17; see also Joel Feinberg, Harmless Wrongdoing: The Moral Limits of the Criminal Law Volume 4 (New York: OUP,1988) 179.
} 
discriminatory manner by refusing to sell a house to B because B is black. However, it is difficult to label A's wrongdoing as exploitation. ${ }^{13}$ Given that $\mathrm{A}$ does not obtain some sort of objective benefit through the transaction with B, A could only be said to 'act exploitatively' towards B. $^{14}$

Wilkinson attempts to abandon the benefit condition in the following example of a slave owner who threatens to punish his slave if the slave does not mutilate him. ${ }^{15}$ Wilkinson argues that the mutilation could not possibly be described as an objective benefit to the slave owner although this relationship is conceivably exploitative. I am not however wholly convinced. First, it could just as easily be argued that the slave owner acts exploitatively but does not actually exploit the slave. Second, even if we accept that this action towards a slave could be exploitative, the benefit condition could conceivably apply to this situation albeit as a broader concept encompassing one's aims, purposes and desires. ${ }^{16}$ Therefore, the slave owner benefits from the alleged exploitation of his slave despite being physically harmed as he achieves his purpose of selfmutilation. The above arguments aside, it strikes me that 'exploitation' is not a particularly apt description of this scenario. Intuitively, coercion or abuse seems to me a better label for the slave owner's wrong.

\section{An Unfair Transaction}

Most people agree that there exists an element of unfairness on an ordinary understanding of exploitation claims. The idea of unfairness is present in many of the criticisms of the organ market. However, a more difficult and theoretically interesting question is what constitutes an unfair transaction?

I do not think that the mere fact that $\mathrm{A}$ gains more than $\mathrm{B}$ necessarily constitutes an unfair transaction. For instance it seems counterintuitive to suggest that a surgeon, who performs a procedure at the going market-rate thereby saving a patient's life, has been exploited given that the patient in having his life saved gained more than he did.

\footnotetext{
${ }^{13}$ ibid Wertheimer.

14 ibid.

${ }^{15}$ Stephen Wilkinson, Bodies for Sale: Ethics and Exploitation in the Human Body Trade (London: Routledge, 2003) 20.

${ }^{16}$ Feinberg (n 12) 193 and Wertheimer (n 7) 210.
} 
Certainly, critics of organ sales do not perceive organ donations as being exploitative even though there is a disparity of value between what the donor and donee gets.

Nor do I think that gaining at another's expense necessarily constitutes an unfair transaction. For example, when playing with a fruit machine in the casino, either the house or I will win. One will gain at the expense of the other. Yet, presuming that the odds are not deliberately weighted against me, we do not say that either of us is exploiting the other. However, Mayer suggests that gaining at another's expense might be unfair and therefore exploitative where B gains less than what he ought to have gained going by the norm of fairness. In other words, gaining at another's expense becomes unfair when the loser suffers some undeserved loss (measured from a baseline of fairness). ${ }^{17}$

The quote above seems to claim that a transaction is unfair and exploitative when we take advantage of another party's weaknesses and circumstances. I disagree. When playing chess, it does not seem unfair to capitalise on an opponent's mistakes and win the game at his expense. This surely is the point of the game. Goodin suggests that the unfairness associated with exploitation lies in playing for advantage where it is inappropriate to do so. ${ }^{18} \mathrm{He}$ provides four scenarios in which this duty might arise of which three are relevant for our present purposes.

First, the duty arises where the other player is unfit or otherwise unable to play for advantage at all. ${ }^{19}$ This is an issue of competence. In the context of organ sales, it will obviously be inappropriate to play for advantage against an incompetent vendor who is unable to make a reasoned, rational decision to enter the transaction. I do not think that any proponents of the organ market would propose the participation of incompetent persons in such a market.

The second scenario is where the other player is hopelessly outmatched. ${ }^{20}$ This is usually framed as an inequality of bargaining power between the rich purchaser and the poor vendor. However, as mentioned, I am not entirely convinced that the purchaser in desperate need for the

\footnotetext{
${ }^{17}$ Mayer (n 11) 140.

${ }^{18}$ Robert Goodin, 'Exploiting a situation and exploiting a person' in Andrew Reeve ed., Modern Theories of Exploitation (London: Sage, 1987) 184.

${ }^{19}$ ibid 185.

${ }^{20}$ ibid.
} 
organ has that much bargaining power over the poor vendor, and vice versa. In fact, evidence suggests that $3^{\text {rd }}$ party middlemen are most likely to exploit the misfortunes of both the vendor and the purchaser. ${ }^{21}$

The final scenario is where one party's relative advantage derives from the other's grave misfortune. ${ }^{22}$ This point seems intuitively true. Consider Nozick's drowning example; ${ }^{23}$ most people think it morally wrong of the rescuer to seek payment for rescuing the drowning victim. Many would think that the rescuer has a moral duty to rescue the victim since it will not cause him much exertion nor put his life at risk.

In spite of this, I am unsatisfied by the argument. First, the drowning example is hardly analogous to our own situation of two desperate parties. Second, whilst I accept that it is reasonable to impute a duty of fairness on individuals (such that the rich organ purchaser owes the poor vendor a fair price for the organ), I am less sure that we as individuals owe a duty of care to just any vulnerable person. Conversely, the drowning example could suggest that the poor vendor ought to donate his organ instead of profiting from the potential purchaser's grave illness. Yet no commentator has advocated encouraging (let alone conscripting) the poor to donate their organs.

There is I think, a crucial distinction between taking advantage of unfairness (where unfairness lies in background circumstances which the advantaged party did nothing to create) and taking unfair advantage of unfairness. ${ }^{24}$ Wetheimer argues that it will be wrong to claim that $\mathrm{A}$ exploits $\mathrm{B}$ when $\mathrm{A}$ makes a reasonable proposal that $\mathrm{B}$ has no alternative but to accept. ${ }^{25}$ Say my vet proposes to treat my pet tortoise's potentially fatal disease for $£ 2000$. The vet takes advantage of my pet's dire need to enter into a transaction with me for his gain, but this is insufficient to render the transaction exploitative. If the proposed price is fair for the useful service rendered (i.e. $£ 2000$ is the market-rate for treatment), then the transaction need not be exploitative even if it is opportunistic.

\footnotetext{
${ }^{21}$ Jason Altman, 'Organ Transplantations: The Need for An International Open Organ Market' (1994) 5 Touro Int'l L Rev 161, 172.

${ }^{22}$ Goodin (n 18) 186.

23 Robert Nozick, 'Coercion', in Sidney Morgenbesser, Patrick Suppes and Morton White (eds), Philosophy, Science and Method: Essays in Honour of Ernest Nagel (New York: St Martin's Press, 1969) 440-472, 449.

${ }^{24}$ Wertheimer (n 7) 232.

25 ibid 22.
} 
Finally, it has been suggested that the poor vendor's consent to the transaction is somehow rendered defective due to his lack of alternatives under the circumstances. This other facet of the unfair transaction argument will be examined in more detail below.

With the above framework in mind, it will be appropriate now to analyse and critique the various types of exploitation claims made with regard to organ sales.

\section{WRONGFUl USE}

That people should treat others as a means to their own ends however desirable the consequences must always be liable to moral objection. Such treatment of one person by another becomes positively exploitative when financial interests are involved. ${ }^{26}$

The above quote was an objection to the practice of surrogacy but could be equally applicable to organ sales. It is often claimed that organ sales are exploitative as they involve, in the Kantian sense, using another person merely as a means to an end and not an end in themselves. ${ }^{27}$ In other words, organ sales are wrong as they fail to respect another as a rational, autonomous being with moral personality.

First, I question if wrongful use is really an exploitation claim at all. Not all improper uses of persons are exploitative. As Wolff notes, venting one's anger by using someone as a punch bag is a wrong in the Kantian sense but we do not normally view it as an exploitative act. ${ }^{28}$ Further, it is unclear from the quote why a failure of respect should be exploitative because financial interests are involved. For instance, a man might take advantage of his lovers' love for him in order to get her to donate him an organ. I think this would present an example of one wrongfully using another in the Kantian sense, even where no financial interests are involved.

Second, I argue that it is not necessarily wrong to use others. We regularly use others - teachers are used by students, doctors by patients; but we do not deem these wrongful. Altruistic donors are presumably

\footnotetext{
${ }^{26}$ Mary Warnock et al., Report of the Committee of Enquiry into Human Fertilisation and Embryology, section 8.17.

27 Immanuel Kant, Groundwork of the Metaphysics of Morals, Mary Gregor ed. (Cambridge: CUP, 1997) 37.

28 Jonathan Wolff, 'Marx and Exploitation' (1999) 3 Journal of Ethics 110.
} 
being used although, ironically, critics do not label this exploitation! We can use others yet treat people as ends in themselves when we invite them to adopt their capacity such that their contribution to ends of ours becomes one of their own ends. ${ }^{29}$ This in turn hinges on the idea of valid consent since it is in this requiring of valid consent that A respects B's autonomy. These issues of consent and coercion will be discussed below.

Finally, I would go further and suggest that setting the raging debate about alienability of parts of a person aside, organ sales could potentially be autonomy enhancing in allowing the vendor and purchaser to exercise their free will to enter into mutually beneficial transactions.

\section{E. HARMful Exploitation}

The argument here is that organ sales benefit rich purchasers at the expense of harming poor vendors. It should be stated from the outset that an 'all things considered' approach has to be taken towards a conception of harm. There are after all negative elements in virtually all uncontroversial beneficial transactions. Indeed, I would prefer not to pay for a good and get it for free instead, but I cannot say that I have been harmed in paying for the good. ${ }^{30}$ The question is whether organ sales by the poor are to be regarded as a net harm. Further, as we are examining organ sales as a social practice, the question is whether organ sales by the poor are typically ex-ante net harmful as a practice. ${ }^{31}$ Employment might result in net harm to the worker who is severely injured on the job, but it does not follow that employment is harmful as a practice.

Assessing the harm caused by paid organ donations to the poor vendor is difficult. Although some studies ${ }^{32}$ have been done to assess the harm or benefit to vendors, they are hardly exhaustive. Moreover it has been suggested that the harm borne by vendors is largely psychological and therefore difficult to assess. ${ }^{33}$ Other studies have shown that advancements in medical science have rendered risks of complications

\footnotetext{
29 John Harris, Wonderwoman and Superman: The Ethics of Human Biotechnology (Oxford: OUP, 1992) 123.

${ }^{30}$ Wertheimer (n 7) 99.

${ }^{31}$ ibid 100.

${ }^{32}$ Madhav Goyal, Ravindra L. Mehta et al. 'Economic and Health Consequences of Selling a Kidney in India' (2002) 288 JAMA 1589.

33 Mark Cherry, Kidney for Sale by Owner: Human Organs, Transplantation and the Market (Washington DC: Georgetown University Press, 2005) 89.
} 
following certain transplantation procedures virtually nonexistent for donors. ${ }^{34}$ However, these do not adequately account for the fact that in many third world countries or indeed the black market, such operations take place in unsanitary conditions with a lack of adequate aftercare for patients. $^{35}$

By weighing the costs of the practice against the benefits, would ensuring a higher price for the organ render the practice less harmful? Unfortunately, higher prices for organs have rarely (if ever) been advocated as a solution. One reason is that increased compensation may add to both negative and positive sides of the ledger. For example, the receipt of monetary compensation may make vendors feel they are doing something undignified and cause some of the psychological harm. ${ }^{36}$ Furthermore, compensation does not adequately overcome the harm done to the vendor by being used merely as a means as opposed to an end.

The moral force of exploitation will be more comprehensively covered but I will make some brief points. First, even where the social practice is ex-ante net harmful, it does not follow that we prohibit it. Smoking is undoubtedly a harmful social practice: it kills and the cost of treating smokers is a massive burden to society. However, we do not prohibit people from doing it. Some distinguish organ sales on the ground that we should not pay people to risk harming themselves. ${ }^{37}$ This is not empirically true since we do not ban people taking dangerous jobs that are altogether more risky endeavours. Second, a black market for organs already exists where a legal market does not; prohibiting the practice does not mean that it will disappear. Finally, provided organs are retrieved in sanitary conditions by a competent surgeon and adequate aftercare is provided, there is no reason to suppose that the same surgical procedure is rendered any more dangerous by the mere involvement of monetary interests.

\footnotetext{
34 Ingela Ferhman-Ekhol, Carl-Gustaf Elinder et al., 'Kidney donors live longer', (1997) 64 Transplantation 976-978.

35 Pranlal Manga, 'A Commercial Market for Organs? Why Not' (1987) 1 Bioethics $321,326$.

36 Alan Wertheimer, 'Two Questions about Surrogacy and Exploitation' (1992) 21 Philosophy and Public Affairs 211, 217.

${ }^{37}$ Wilkinson (n 15) 108.
} 
It could be asked then if the welfare of potential organ vendors will be better served by a legal, regulated market for organs. In light of the above, I think that they are.

\section{F. Mutually Advantageous Exploitation}

Can A (the purchaser) exploit B (the poor organ vendor) if B gains from the transaction and is not rendered worse off than he would have been if he had not entered the transaction? This sometimes seems to be the situation with organ sales. Some opine that harm is a necessary condition of an exploitative transaction. ${ }^{38}$

I am however inclined to agree with Wertheimer that such a transaction could nonetheless be exploitative. ${ }^{39}$ Whilst B could have gained relative to a non-cooperation baseline (i.e. where the transaction never occurred), he could nonetheless be exploited if the distribution of social surplus is unfair to $\mathrm{B} .{ }^{40}$ As Mayer puts it, B gains less/pays more than what he ought to have gained/paid going by the norm of fairness. ${ }^{41}$ Thus, while I may have benefitted from my pet tortoise being treated, the transaction could nonetheless be exploitative if the vet is charging me more than what is fair, for instance if he charges me $£ 2000$ where the fair price would be $£ 200$.

The difficulty is specifying what exactly fairness (and thus the fair price) entails. Some might suggest that a fair transaction is one in which both parties gain just about equally. As previously demonstrated however, the mere fact that one party gains more than the other would not necessarily render the transaction exploitative. Alternatively it is suggested that the fair (non-exploitative) price is the hypothetical market price, a price set by a 'fairly conducted market in the absence of fraud, monopoly or coercion. ${ }^{42}$ This might be relatively easy to identify where there is a competitive market with complete information. As Fabre notes

\footnotetext{
38 Allen Buchanan, Ethics, Efficiency and the Market, (Oxford: Clarendon Press, 1985) 87.

${ }^{39}$ Wertheimer (n 36) 222.

${ }^{40}$ Wertheimer (n 7) 22.

${ }^{41}$ Mayer (n 11) 141.

${ }^{42}$ Raymond de Roover, 'The Concept of the Just Price: Theory and Economic Policy', (1958) 18 Journal of Economic History 418, 420-421.
} 
however, the organ market is a pressurized one..$^{43}$ Those who want to sell their organs would rarely do so if they could raise money through other means and those who want to purchase organs tend to be in desperate need of them. It is thus impossible to compare it to prices for organs bought and sold under normal (non desperate) conditions. ${ }^{44}$ Further the desperation on either side makes it is difficult to assess whether the distribution of gains is indeed unfair.

I do not propose to give an alternative account of fairness in this paper. Instead I wish to highlight the moral significance of the fair price. It is the price at which neither party takes special unfair advantage of particular defects in the other party's decision making capacity or vulnerabilities in the other party's situation. ${ }^{45}$ It will be unfair for the poor organ vendor to be paid less for his organs than what he might ordinarily expect to be paid simply because of his desperate situation. Should we decide to construct an ethical market, this non-exploitative price and how it could be derived will be a concern.

\section{G. Questions of CONSENT AND COERCiON}

There is little argument that the complete lack of consent alone would provide a reason independent of exploitation to invalidate a particular transaction. Nonetheless, consent and coercion are inextricably tied up with various exploitation claims. For example, valid consent could plausibly defeat wrongful use exploitation claim.

A preliminary question that arises is whether coercion or the lack of valid consent is a necessary condition of exploitation (although the moral force of coercion and the lack of valid consent is significant regardless of the view one takes on this). Wertheimer argues that exploitation requires minimally some defect in choice because A does not exploit B when B makes an entirely voluntary and altruistic transfer of disproportionate value to $\mathrm{A}^{46}$ Indeed he thinks it odd to say that a hospital exploits its volunteer workers just because they are volunteers who choose not to get

${ }^{43}$ Cecile Fabre, Whose Body Is It Anyway?: Justice and Integrity of the Person (Oxford: Clarendon Press, 2006) 144.

${ }^{44}$ ibid.

${ }^{45}$ Wertheimer (n 7) 232.

${ }^{46}$ Wertheimer (n 7) 25. 
paid. ${ }^{47}$ Schwartz argues that valid consent is what distinguishes exploitation from gifts; A only exploits B when B's consent is invalid. ${ }^{48}$ As such, altruistic donation is not considered exploitative, not because the exchange of values is fairer but because the motivation underlying the transaction is more pure (though one could question this since it is plausible that one could be coerced into being 'altruistic').

Yet as Wood notes, typical victims of exploitation are all too willing to consent to their exploitation owing to the absence of less bad alternatives. ${ }^{49}$ Although the alleged victim might prefer to have a different range of options available, he can nonetheless make a perfectly rational decision as to the advisability of the various options. The exploited party might have validly consented to the unfair price but we could nonetheless argue that he has been exploited as he is worse off than he would have been if the exploiter paid him a fair price. What is less clear here is whether the absence of less bad alternatives would result in some defect in the quality of the victim's consent.

\section{Valid Consent}

We need to examine the concept of valid consent. Logically, the exploited party needs to at least consent to entering the transaction. There is however a distinction between valid and invalid consent. An invalid consent is perfectly real, for instance when I hand over my money in response to a robber's threat against my life. Yet such consent evidently does not have the same moral significance as valid consent. First, where there are defects in consent, we would not fail to respect B's autonomy if we fail to respect B's decision. Second, to the extent that B's consent is defective, B's responsibility to fulfil the transaction is mitigated. Finally and significantly in the context of exploitation, to the extent that B's consent is defective, we have less reason to assume that the transaction is advantageous to B. ${ }^{50}$

For consent to be valid there must be three main elements present in sufficient quantity: information, competence and voluntariness. ${ }^{51} \mathrm{~A}$

\footnotetext{
47 ibid.

${ }^{48}$ Schwartz (n 8) 162.

49 Allen W. Wood, 'Exploitation' (1995) 12 Social Philosophy and Policy 136, 149.

${ }^{50}$ Wertheimer (n 7) 253.

${ }^{51}$ Wilkinson (n 15) 76.
} 
distinction between a defect in B's capacity as a decision maker within B's objective situation (competence) and a defect in B's objective situation itself (information) should be drawn. ${ }^{52}$

In the former, consent is not defective when B has: the ability and information necessary to understand the options available; the ability to understand/predict the consequences of those options and the ability to relate the consequences of these options to his own values. ${ }^{53}$ It is often argued that the promise of money could somehow compromise the above and result in cognitive errors on the part of the poor vendor. ${ }^{54}$ This seems plausible, but it seems unfair to presume without further evidence that a poor individual might be any more susceptible to the promise of money than any other or that he does not objectively consider the pros and cons of a proposal. I think it as likely that ties of kinship could compromise one's capacity to make rational decisions, but this has not been raised with regards related organ donations. In my opinion, the better solution would be to provide as much information about the procedure as is reasonable to the vendor to ensure that the vendor is making an informed decision.

Information matters as $\mathrm{B}$ needs to know what $\mathrm{X}$ is and what the likely consequences of $\mathrm{X}$ are in order to consent to $\mathrm{X}$. It seems fair to state that the potential vendor would at least need to know about the potential drawbacks and dangers of the procedure and possible future health consequences. ${ }^{55}$ Needless to say however, full or complete knowledge is not required (nor will it be ever possible).

The third element of valid consent is the voluntariness of the decision. To act voluntarily is to be free from coercion. Dworkin suggests that one is coerced when one's will is subordinated to another and is thus no longer a completely independent agent. ${ }^{56}$ In my opinion, this is a definition that begs the question: when exactly is one's will subordinate to another?

Wertheimer suggests that proposals are coercive when one party (A) threatens to make another (B) worse off relative to some baseline,

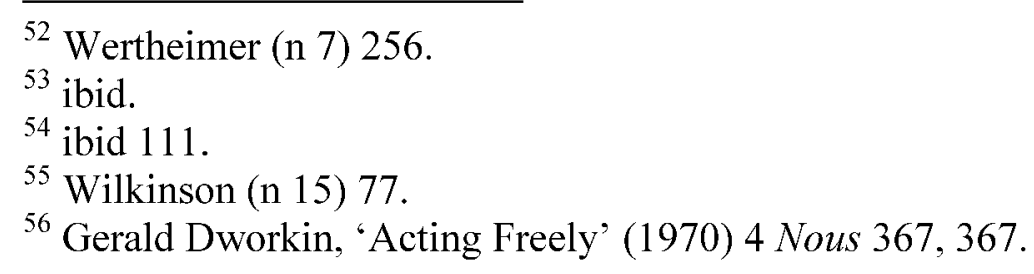


unless $\mathrm{B}$ does $\mathrm{X} .^{57}$ To understand this, we revisit the vet who proposes to treat my pet tortoise for $£ 2000$. Is there a real distinction between him and the tortoise killer who threatens to kill my pet tortoise unless I pay $£ 2000$ ? According to Wertheimer's definition of coercion, the answer is yes. Unlike the tortoise killer, the vet is not proposing to harm me if I do not pay but offers a benefit if I do. Now, if the vet has a freestanding obligation to treat my tortoise (say if I had already paid the actual price of $£ 500$ as required) and proposed not to act on it unless I paid more, then we could rightly view his proposed omission as being coercive. Thus, coercion seems to be a multiple baseline concept and is dependent on the context in which it takes place. ${ }^{58}$

Dworkin then raises an interesting proposition: why should coercion be thought of as getting someone to do something he does not want to do as opposed to a way of getting someone to want to do something else $?^{59}$ To this, I suggest that it really depends on a description of what he wants or does not want to do. For instance, the tortoise killer's threat could be thought of as getting me to pay $£ 2000$, something I did not want to do. Alternatively, the same threat could be thought of as getting me to want to pay the $£ 2000$ as opposed to not paying and watching my pet die. On this view then, Dworkin's conception of coercion might not be so different from Wertheimer's after all.

Wertheimer's account of coercion suggests that the lack of alternatives alone would not render the situation coercive. In my opinion, the plight of the poor vendor is rather like my situation with the vet. No one is threatening to make the vendor worse off than he already is if he does not choose to exercise the option.

\section{Hard Circumstances and the Lack of Choice}

Scanlon argues that choice is not enough; people may reasonably demand to shape their lives and obligations through the exercise of choice under reasonably favourable conditions. ${ }^{60}$ It is thus argued that where organ sale is a choice out of many unacceptable ones, the poor vendor has no real

\footnotetext{
${ }^{57}$ Wertheimer (n 36) 213.

${ }^{58}$ Wilkinson (n 15) 95-96.

${ }^{59}$ Dworkin (n 56) 383.

${ }^{60}$ Thomas M. Scanlon, 'The Significance of Choice' in Tanner Lectures on Human Values, Vol.8 (Salt Lake City: University of Utah Press, 1988) 184.
} 
choice. Whilst this seems intuitively true, it is also strange to presume that the lack of alternatives alone would always invalidate consent. For example, when the individual has to choose between amputating a leg or dying; surely we do not say that the individual cannot validly consent to the amputation procedure merely for the want of a better alternative? In my opinion, even hard circumstances do not rule out an autonomous choice by an individual to choose $\mathrm{X}$ where features of such an autonomous choice are present.

Moreover, even if we accept that the presence of such background conditions might diminish the moral quality of one's choice (although we are unsure if it diminishes it to the extent that there is no valid consent at all), it does not tell us how we should deal with this. ${ }^{61}$ Instead of prohibition, we could say that the hard circumstances are the problem and the solution would be to expand the choices available to the poor by alleviating their poverty. As Radcliffe-Richards notes, trying to end exploitation by prohibition is as futile as ending slum dwelling by bulldozing slums; it will be heaping insult upon injury if we remove another option from the already meagre alternatives available to the poor. ${ }^{62}$ Further, as will be explored below, a morally defective choice might not necessarily justify prohibition.

I think it unlikely that critics will find organ sales more acceptable if the vendor were rich. Otherwise, I suggest that the solution might well be to set a minimum income level the vendor must reach before being allowed to sell an organ. However, this would paternalistically prevent the poor potential vendor from entering a potentially exploitative transaction, ironically at the expense of discriminating against them.

Finally, does valid consent to the exploitative transaction get the parties off the moral hook? My answer is no. It might be morally wrong of the exploited to consent to being exploited and it might also be morally wrong of the exploiter to facilitate the exploited party's participation in an exploitative transaction. Even if it cannot be morally worse for me to engage in an exploitative transaction where the other party benefits from the exploitative transaction relative to no transaction at all, it might

\footnotetext{
${ }^{61}$ Wertheimer (n 7) 276.

62 Janet Radcliffe-Richards et al., 'The Case for Allowing Kidney Sales' in Helga Khuse and Peter Singer (eds) Bioethics (Blackwell, 2006) 488.
} 
nonetheless be a serious moral wrong for me to do so. ${ }^{63}$ The gravity of my action is not diminished by the exploited party having worse options on the table.

\section{H. The Moral Force of Exploitation Arguments in Organ SALES}

Even if we accept that organ sales as a practice could be exploitative in the ways demonstrated above, it does not necessarily follow that we are justified in prohibiting organ sales. When dealing with exploitation claims, we have to weigh the wrongs associated with exploitation in organ sales against the moral justifications for permitting and enforcing organ sales.

The two main moral justifications for organ sales are the promotion of autonomy and welfare of individuals. First, it is morally valuable that individuals can autonomously make choices for themselves. I accept that there is a plausible argument that the vendor's 'true' freedom includes proper self-development and that organ sales would detract from the ideal of human flourishing that society should seek to foster. ${ }^{64}$ In my opinion however, the right to make a bad choice is a crucial dimension of autonomy. Whilst the exercise of autonomy alone is not sufficient to constitute a morally valuable choice, autonomous good choices are only possible where one is allowed to make an autonomous bad choice. Second, potential organ vendors and purchasers should be allowed to use the means available to them to improve their lives where the benefit to them will outweigh any potential harm.

We turn now to the moral justifications for the prohibition or more generally, state intervention in organ sales.

\section{Paternalistic Intervention}

If organ sales are a form of harmful exploitation, are paternalistic restrictions on organ sales justified? Our task here is made relatively easy as we have many examples in the law that prohibit parties from engaging in transactions that could be harmful to themselves. It is not clear though in the case of harmful exploitation whether exploitation is even the

\footnotetext{
${ }^{63}$ Feinberg (n 12) 181 and Wertheimer (n 7) 289.

${ }^{64}$ Wertheimer (n 36) 233.
} 
driving moral force behind prohibiting the transaction. I would suggest that the harm itself is sufficient to justify a prohibition. We might be in a better position to consider the moral force of exploitation if we focus on mutually advantageous exploitation. ${ }^{65}$

Could the state intervene if it is morally bad for participants to consensually participate in such exploitative transactions (moral paternalism)? Perhaps; but I argue that the moral value attached to acting autonomously and the non-moral potential welfare benefits to each party could outweigh the moral badness of participating in such a transaction.

\section{Perfectionist Arguments}

Some might argue that there are moral reasons for prohibiting exploitative transactions that are not rooted in appeals to the non-moral, welfare interests of the various parties to that transaction. ${ }^{66}$ For instance, it has been argued that exploitative transactions tacitly endorse the inequality of society and are inconsistent with important values (like justice) that society holds dear. Philosophers like Nagel hold the view that it is wrong to allow unjust transactions to occur even when these transactions are not bad for anyone. ${ }^{67}$

Wertheimer disagrees with the above and begins by arguing that exploitation is not commonly viewed as a wrong against society. ${ }^{68}$ In light of the strong views expressed by various commentators above, this argument does not ring entirely true. He further states that it is not clear if society should seek justice even at a cost to its members; in fact society does not do so, as evidenced by the distinction between criminal and civil law. ${ }^{69}$ I certainly do not think that this is an argument against the idea that the law ought to take exploitation more seriously. However, I propose that there is good reason for society to refrain from seeking justice by perpetrating injustice towards a class of people who are already less welloff. Finally, Wertheimer argues that it is unclear if justice has any independent moral weight apart from its effect on people's welfare. ${ }^{70} \mathrm{He}$

\footnotetext{
${ }^{65}$ ibid 231.

${ }^{66}$ Wertheimer (n 7) 305.

${ }^{67}$ Thomas Nagel, Equality and Partiality (New York: OUP, 1991) 107.

${ }^{68}$ Wertheimer (n 7) 309.

${ }^{69}$ ibid.

${ }^{70}$ Wertheimer (n 36) 236.
} 
points out that Nagel himself adds that this unfairness may be overridden by "countervailing factors including benefits to the worse-off". ${ }^{71}$

To conclude, I do not think that the perfectionist argument as framed above justifies prohibition of the practice of organ sales. I stress however that such arguments cannot be dismissed as mere attempts at justifying the moral repugnance felt towards such transactions. Care must be taken to evaluate these freestanding moral reasons for prohibition.

\section{Background Injustices and the Duty to Protect the Vulnerable}

Goodin suggests that exploitation is based on a violation of a moral norm - the duty to protect the vulnerable, which can be likened to a duty of care towards the vulnerable. ${ }^{72} \mathrm{We}$ have a moral responsibility to protect the interests of those who are particularly vulnerable to our actions and choices regardless of the source of their vulnerability. ${ }^{73}$ The duty is a two part one: first, it involves us refraining from pressing one's advantage against the vulnerable in a way that would be permissible in ordinary everyday relationships. Second, it involves taking positive steps to assist those who are particularly vulnerable to you. ${ }^{74}$ Whilst both parties do not have an obligation to transact, it is suggested that if there is a transaction, both parties must not neglect the other's needs particularly if each party is in a position to provide for those needs.

There are several arguments against this. As previously mentioned, I do not think that such a duty exists especially if one party bears no special responsibility for causing or alleviating the other's suffering. ${ }^{75}$ Even supposing that such a duty exists, Wertheimer argues (and I concur) that it is the responsibility of society as a whole to assist the particularly vulnerable. It would be hypocritical to say that 'because we have failed to repair your background conditions we will not let you improve your situation on terms that are fair given these background conditions (i.e. by prohibiting organ sales). ${ }^{, 76}$ Finally, our duty towards the vulnerable need not necessarily be best fulfilled through the outright prohibition of organ

\footnotetext{
${ }^{71}$ Nagel (n 67) 107.

${ }^{72}$ Goodin (n 18) 187.

73 ibid.

74 ibid.

${ }^{75}$ Wertheimer (n 7) 298.

${ }^{76}$ ibid 299.
} 
sales but by ensuring that the needs of the vulnerable are met in the design of the organ market.

\section{Strategic Intervention}

The starting point is to look at whether a set of actions will be harmful to a class. ${ }^{77}$ Strategic intervention may be justified where we want to protect this class (in our case, the poor) from being exploited, regardless of the effect on the particular individual. Unlike paternalism though, strategic interventions seek improvements in welfare for potential exploitees by facilitating the disadvantaged party's own judgment about his or her interest. This is achieved by improving the bargaining situation so that the disadvantaged party is better able to obtain what he or she deserves. ${ }^{78}$ Unlike the perfectionist arguments, strategic intervention justifies restrictions on liberty on 'grounds of what is good for people (welfare) as contrasted with what is good simpliciter. ${ }^{, 79}$

Assuming that society is justified in intervening in the transaction for the aforementioned reasons, the legal regime could pursue one of several strategies. The legal regime could set out the terms of the transaction; state that the transaction will not be enforced if it is unfair or determine what the exploiter will get if the terms are unfair. ${ }^{80}$ In light of the many arguments made above, it seems that the welfare of the class of vendors is best served by the first strategy. The strategic argument therefore does not look likely to justify the banning of all organ sales but rather the creation of a regulated market.

\section{Selling Organs Ethically}

Throughout this paper, I have attempted to demonstrate that the prohibition of organ sales cannot be justified on moral or welfare grounds. On the contrary, regulation seems to be the key. An ethical market should address the concerns of preventing wrongful exploitation of individuals by setting a fair price, ensuring that vendors get the information necessary to make a correct decision and protecting vulnerable individuals from

\footnotetext{
77 ibid 300 .

78 ibid 304.

${ }^{79}$ ibid 305.

${ }^{80}$ ibid 302.
} 
coercion and harm. In this final section, I focus in particular on Erin and Harris' proposed creation of a monopsonistic market as an ideal model. ${ }^{81}$

The proposed market will be a geographically contained one (as opposed to an international market), so as to prevent the one way flow of organs from poorer to more affluent nations. ${ }^{82}$ However, this is arguably not feasible particularly given the existence of medical tourism and the international black market. Further as Radcliffe-Richards notes, although much of international trade is objectionable on the same grounds of one way traffic and the exploitation of the poor, it is thought a better solution to improve the conditions of trade than to prevent it altogether. ${ }^{83}$ Both objections are, in my opinion, fair. I will however point out that it will be virtually impossible to monitor the welfare of the donors in a foreign country; the extent to which this defeats having the monopsonistic market in the first place is less clear.

As the term 'monopsonistic' suggests, there will be only one purchaser in the market. In the context of the UK, this is likely to be a centrally regulated governmental body like the NHS. Such a requirement though is likely to be problematic in countries without a national healthcare system like the USA. The sole purchaser would be responsible for ensuring the equitable distribution of all organs and tissues purchased, that organs are adequately screened and matched before transplantation and that vendors are given as much as information as is possible to make a decision. Adequate aftercare should also be provided to vendors. The purchaser would set the price paid for an organ according to that which an organ might get according to a fairly conducted market. ${ }^{84}$

The first problem is cost. Such a state run organ-purchasing programme is likely to be very expensive. It has been empirically proven however that sick persons in need of organ transplants are likely to cost the state more in the long run. The NHS saved $£ 46.1$ million in dialysis

\footnotetext{
${ }^{81}$ Charles A, Erin and John Harris, 'A monopsonistic market: or how to buy and sell human organs, tissues and cells ethically', in Ian Robinson ed., Life and Death under High Technology Medicine, (London: Manchester University Press in association with the Fulbright Commission, 1994).

${ }^{82}$ Charles A. Erin and John Harris, 'An ethical market in human organs' (2003) $29 \mathrm{~J}$ Med Ethics 137.

${ }^{83}$ Janet Radcliffe-Richards, 'Commentary: An ethical market in human organs' (2003) $29 \mathrm{~J}$ Med Ethics $139,140$.

${ }^{84}$ Erin and Harris (n 81) 140-141.
} 
costs with the 1914 kidney transplants that took place from 2005 to $2006 .{ }^{85}$ The second problem is determining the fair price. As previously mentioned, we are unlikely to know what the fair price for an organ is since the market for organs is largely hypothetical. Further there might be a conflict of interest since the purchaser would have the incentive to set as low a price as possible. Erin and Harris argue though that this might not necessarily be the case since prices still have to be sufficiently high to attract would-be organ vendors. ${ }^{86}$

In addition to the aforementioned benefits to the vendor and patient, the legalisation of organ sales will also effectively mean that vendors and purchasers now have recourse to the law to enforce the transaction. Commercialising organ procurement will have the advantage of introducing special legal safeguards, for example product liability. ${ }^{87}$

The more difficult question to address is if there is a good enough reason to rule out the many potential sales that the monopsonistic market will prevent? Radcliffe-Richards queries if it is legitimate for us to deprive people of the opportunity to go outside of the regulated system and engage with the free market. ${ }^{88}$ This is especially significant since public health services can sometimes be inadequate, and it is accepted within the NHS system at least that those who find it inadequate may go outside it. Yet, it is equally valid to argue that protecting parties from exploitation is a justification in its own right for excluding a free market choice. On a more practical note, I suggest that a zealously regulated market is the political price that must be paid to gain public backing for a market for organs in the first place.

In conclusion, we recognise the legitimacy of some exploitation claims within the morass of objections against the practice of organ sales. However, as demonstrated above, the force of these claims points us towards regulation and not prohibition of such sales. There is a good case to be made for an ethical market for organs that deals with such objections and ultimately improves the welfare of those who participate in it.

\footnotetext{
${ }^{85}$ UK Transplant The Cost Effectiveness of Transplantation (UK Transplant, 2007), available at $<$ www.uktransplant.org.uk $>$ accessed on 24 September 2012.

${ }^{86}$ Erin and Harris (n 81) 141.

${ }^{87}$ Cherry (n 33) 111.

${ }^{88}$ Radcliffe-Richards (n 83) 140.
} 